Canadian

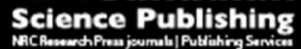

Canadian Journal of Physiology and Pharmacology Revue canadienne de physiologie et pharmacologie

\title{
Virtual Morris Task Responses in Individuals in an Abstinence Phase from Alcohol
}

\begin{tabular}{|c|c|}
\hline Journal: & Canadian Journal of Physiology and Pharmacology \\
\hline Manuscript ID & cjpp-2017-0013.R2 \\
\hline Manuscript Type: & Article \\
\hline Date Submitted by the Author: & 23-Mar-2017 \\
\hline Complete List of Authors: & $\begin{array}{l}\text { Ceccanti, Mauro; Uniroma } 1 \\
\text { Coriale, Giovanna; Uniroma } 1 \\
\text { Hamilton, Derek; University of New Mexico } \\
\text { carito, valentina; National Research Council of Italy (C.N.R.), Institute of } \\
\text { Cell Biology and Neurobiology } \\
\text { Coccurello, Roberto; National Research Council of Italy (C.N.R.), Institute } \\
\text { of Cell Biology and Neurobiology } \\
\text { Scalese, Bruna; CRARL Lazio } \\
\text { Ciafre', Stefania; ibcn cnr } \\
\text { Codazzo, Claudia; Uniroma1 } \\
\text { Messina, Marisa Patrizia; CRARL Lazio } \\
\text { chaldakov, george; laboratory cell biology } \\
\text { Fiore, Marco; IBCN-CNR, Institute of Cell Biology and Neurobiology }\end{array}$ \\
\hline $\begin{array}{r}\text { Is the invited manuscript for } \\
\text { consideration in a Special } \\
\text { Issue?: }\end{array}$ & $\mathrm{N} / \mathrm{A}$ \\
\hline Keyword: & Alcoholism, Virtual Morris Task, Gender, Cognition, Spatial Memory \\
\hline
\end{tabular}

\section{SCHOLARONE ${ }^{m}$ \\ Manuscripts}




\title{
Virtual Morris Task Responses in Individuals in an Abstinence
}

Phase from Alcohol

\author{
Mauro Ceccanti ${ }^{a}$, Giovanna Coriale ${ }^{a}$, Derek A. Hamilton ${ }^{b}$, Valentina \\ Carito $^{c}$, Roberto Coccurello ${ }^{c}$, Bruna Scalese ${ }^{a}$, Stefania Ciafre'c, \\ Claudia Codazzo ${ }^{\text {a }}$, Marisa Patrizia Messina ${ }^{a}$, George N. Chaldakov ${ }^{d}$, \\ Marco Fiore \\ ${ }^{a}$ Center for Alcohol Abuse (Centro Riferimento Alcologico Regione Lazio-CRARL), \\ Department of Clinical Medicine, Sapienza University of Rome, Italy \\ ${ }^{\mathrm{b}}$ Department of Psychology, University of New Mexico, Albuquerque, NM, USA \\ ${ }^{c}$ Institute of Cell Biology and Neurobiology, National Research Council (IBCN-CNR)/Santa Lucia \\ Foundation - Rome, Italy \\ ${ }^{d}$ Laboratory of Cell Biology, Department of Anatomy and Histology, Medical University, Varna, \\ Bulgaria
}

Running head: spatial memory in alcoholics

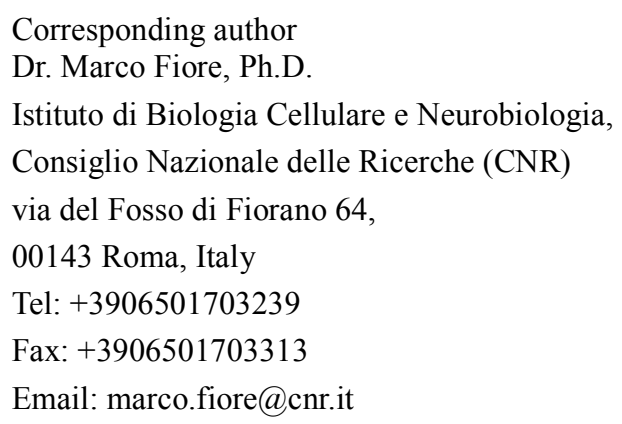




\begin{abstract}
The present study was aimed at examining spatial learning and memory in 33 men and 12 women with alcohol use disorder (AUD) undergoing ethanol detoxification by using a virtual Morris task. As controls, we recruited 29 men and 10 women among episodic drinkers without a history of alcohol addiction and/or alcohol related diseases. Elevated latency to the first movement in all trials was observed only in AUD persons, furthermore, control women had higher latencies compared to control men. Increased time spent to reach the hidden platform in the learning phase was found for women of both groups compared to men, in particular during trial 3. As predicted AUD persons (more evident in men) spent less time in the target quadrant during the probe trial, however, AUD women had higher latencies to reach the platform in the visible condition during trials 6 and 7 that resulted to be associated higher distance moved. As for the probe trial men of both groups showed increased virtual locomotion compared to the women of both groups. The present investigation confirms and extends previous studies showing $i$ : different gender responses in spatial learning tasks; $i i$ : some alterations due to alcohol addiction in virtual spatial learning and iii: differences between AUD men and AUD women in spatial behavioural related paradigms.
\end{abstract}

\title{
Keywords:
}

Alcoholism, Virtual Morris Task, Gender, Cognition, Spatial Memory 


\section{Introduction}

Heavy alcohol consumption is known to be associated with changes across several domains of cognition including executive functioning and memory domains (OscarBerman and Marinkovic 2003, 2007). Indeed in alcoholics, most of the principal memory components are affected, including spatial memory, working memory, episodic memory, semantic memory, perceptual memory, and procedural memory (Pitel et al. 2014). The extent of those cognitive impairments depends on several factors, such as age, gender, nutritional status, and psychiatric comorbidity. Nevertheless, recovery of memory abilities has been described with abstinence in uncomplicated persons with alcohol use disorder (AUD) (Novier et al. 2015 for review). It has been shown that in young adults (approximately 21 years), binge drinking is associated with deficits in cognitive functions related to the dorsolateral prefrontal cortex, as well as alterations in memory functions, associated with the temporal lobe (Scaife and Duka 2009). Adolescents after a period of three weeks of withdrawal had a lower verbal learning and a lower visual reproduction (Brown et al. 2000). In adult AUD people, impairments on word recall were detected after a 3-weeks-long abstinence (Schottenbauer et al. 2007) whereas long-lasting disruptions in spatial processing were revealed after a longer abstinence, but other domains of cognitive functioning recovered with prolonged abstinence (Fein et al. 2006). Quite interestingly, it has also been demonstrated that adults with elevated risk for alcohol abuse, but who do not yet meet diagnostic criteria, verbal learning was affected by binge drinking, whereas spatial learning appeared to be not fully compromised (Sneider et al. 2013a). In an other report on the toxic effects of alcohol on cognition it was shown that even at a subsyndromal level young adults make risky decisions mimicking those observed in individuals with alcohol-associated diseases (Harvanko et al. 2012). Moreover, acute or binge drinking affects executive- 
type cognitive functions, working memory and pattern recognition tasks (Weissenborn and Duka 2003). Previously reported human studies showed spatial impairments in detoxified AUD people (Beatty et al. 1996; Kramer et al. 1991) or motor control, attentional and motivational deficits (Ceccanti et al. 2015b). However, there are not studies on spatial cognition that did take into account gender differences.

As for sex differences, it is well known that men and women respond quite differently to ethanol addiction (reviewed in Erol and Karpyak 2015; Holmila and Raitasalo 2005). Compared to men, women are lifetime abstainers, drink less, and are less likely to engage in drinking problems, develop alcohol-related disorders or alcohol withdrawal symptoms. However, women who drink excessively develop more medical complications. Biological (sex-related) factors, including differences in alcohol pharmacokinetics as well as alcohol effects on brain function and the levels of sex hormones, may contribute to some of those differences (Nixon et al. 2014). Evidence indicates that sex-related factors are interacting with alcohol use in a complex manner, which differentially impact the risk for development of the behavioural or medical problems in men and women.

Notably, a large literature on gender differences in humans on spatial memory and navigation, is available evidencing gender differences possibly linked to differences in the strategy put in action to navigate (Bosco et al. 2004; Saucier et al. 2002) and are usually detected more in the learning paradigm than in the recalling ones (Palermo et al. 2008; Piccardi et al. 2008). It should be noted that in AUD people gender matters because could have an impact at two different levels: one level (i.e., physiological level) is specific to the response to ethanol addiction; the other is a cognitive level (spatial navigation/memory performance could be different among the two genders). Thus AUD men and AUD women can behave differently in spatial memory/navigation because $i$, the ethanol might affect in a different way neuronal substrates involved in these skills, $i$, ethanol addiction can differently impact on skills that are already different at "baseline" 
or a combination of these factors.

Thus, the aim of the present study was to examine, in men and women with alcohol dependence undergoing ethanol detoxification compared to controls with no history of alcohol abuse or alcohol related disorders, spatial memory function by using a virtual analogue of the Morris water task to analyze spatial memory (Ceccanti et al. 2015b; Hamilton et al. 2002, 2009). 


\section{Materials and methods}

\subsection{Participant recruitment}

Participant descriptions are reported in Table 1. The study included at the beginning 146 AUD men and 62 AUD women but following the exclusion criteria described later the testing was carried out on 33 AUD men and 12 AUD women subjected to detoxification including some male participants of a previous study (Ceccanti et al. 2015a). The participants were recruited in the "Centro di Riferimento Alcologico della Regione Lazio" of Policlinico Umberto I, Sapienza University Hospital, in Rome, Italy. Trained psychologists conducted diagnostic clinical interviews by using the Structured Clinical Interview for Diagnostic and Statistical Manual (DSM-IV) Non-Patient Edition (SCIDI/NP) (First 1997). All recruited alcoholics met the DSM-IV criteria for alcohol dependence. The AUD people also underwent two semi-structured interviews to assess lifetime alcohol consumption. The Life Drinking History-L.D.H. (Skinner and Sheu 1982) and Time Line Follow Back -T.L.F.B. (Sobell 1992) were used to assess alcohol consumption from the first year of regular drinking and specific amounts of alcohol consumed over the past six months respectively. Participants were asked to perform the virtual Morris task only after the disappearing of the withdrawal symptoms according to a set of specific evidences, such as elevated blood pressure, tachycardia, tremor, sweating (see cumulative abstinence days - CAD - in Table 1).

\section{Table 1 here}

As controls, we recruited among moderate drinkers 29 men and 10 women without a history of alcohol dependence and/or alcohol related diseases. We selected moderate drinkers because based on our personal experience persons who don't drink alcohol are difficult to recruit according to the exclusion criteria described below. 
According to the indications of the drinking levels of National Institute on Alcohol Abuse and Alcoholism (http://www.niaaa.nih.gov/alcohol-health/overview-alcoholconsumption/alcohol-facts-and-statistics accessed on 3/17/2016) we considered moderate drinkers people drinking up to 2 drinks per day (in Italy 1 drink $=12 \mathrm{~g}$ of alcohol). Exclusion criteria for all participants included zero alcohol level measured by a breath-analyser at the time of the experimentation, history of head injury, loss of consciousness, history of organic mental disorder, present assumption of psychoactive drugs (as cocaine, opioids, amphetamine, other recreational drugs, anxiolytics, euphoriants, antipsychotics, barbiturates, benzodiazepines, antidepressants, hallucinogens - data based on urine analyses), seizure disorder or central nervous system diseases and no sign of hypertension at the time of recruitment. Another exclusion criterion for all participants was the lack of familiarity with the use of a computer. Blood alcohol levels were measured in all participants by using Alcoscan AL7000. All participants provided written informed consent after receiving a complete description of the study. The study was approved by the university hospital ethics committee at (Sapienza Universita' di Roma, Italy), and all study procedures were in accordance with the Helsinki Declaration of 1975, as revised in 1983, for human experimentation.

\subsection{Virtual Morris water task}

A virtual version of the Morris Water Maze was used (Hamilton et al. 2002, 2009) with minor modifications (Fiore et al. 2002; Hamilton et al. 2003). We examined only a single time to avoid any kind of habituation profile in the responses to the virtual task. It consists of the display of a square environment containing a circular pool of water as shown in Fig. 1 (see Hamilton et al. 2003). Four rectangular drawings that were distinguishable by their size, colour, and placement on the walls surrounding the pool, served as navigational cues to support orientation. Each cue was placed on a different 
wall of the room and stretched from the ceiling to the pool wall. Participants navigated in the pool from a first-person perspective and moved around by using the 'up', 'left' and 'right' arrow cursor keys of the keyboard. Following methods previously described (Skelton et al. 2000) to more closely mimic typical rodent behavior, the 'back' arrow key was disabled to not permit participants to back up. If participants needed to turn around, they had to spin $180^{\circ}$ around their left or right axis using the right or left arrow keys. Participants performed the experiment on a PC with a 21-inch monitor in a room without windows of the Centro Riferimento Alcologico Regione Lazio, Rome, Italy. Participants were told that after completion of a trial, the screen would be clear and the enter key on the keyboard must be pressed to start the next trial. The starting position of each trial was randomly chosen by the computer software to not induce direction pathways' preferences. In order to limit the procedure to a maximum of $15 \mathrm{~min}$ to not affect participants' concentration and motivational abilities patients and controls were subjected to a total number of 7 consecutive experimental trials. Indeed, testing consisted (without any training trial) of four trials (learning phase) where the participants had to navigate to the hidden platform located in the North-East quadrant (target); if they swam over the area of the pool where the platform was located, a tone sounded, the platform raised out of the water and a message saying "congratulations" was displayed. If 120 seconds elapsed without platform retrieving by participants, the platform was raised out of the pool so that it was visible and a message appeared "Time has expired. Please swim toward the platform". After the learning phase, participants underwent a single platform-less trial (probe trial). In the probe trial, there was no indication for the participants that the probe trial was different from the learning phase until it was completed. These trials allowed examination of where in the pool the participant searched for the platform without receiving feedback. The logic is that the participant by using the spatial cues to locate the platform would spend the majority of their swimming during the probe trial in the target quadrant of the pool. Upon the 
conclusion of the probe trial, the platform was raised out of the water so that it was visible to the participants. This last phase is referred to as "visible platform phase" and consisted of two trials. All events and consequences were identical to those of the previous phases. The visible platform phase is aimed to assess possible attentional, motivational, locomotor or perceptive difficulties due to the interaction with a workstation. Data analyzed were: $i$, the latency to the first movement in all trials; $i i$, the latency to reach the hidden platform in the learning phase; iii, the latency to reach the visible platform; $i v$ the total distance moved in all trials; $v$, the time spent in $\%$ in the quadrants with the hidden platform (probe trial).

\section{Figure 1 here}

As for the reliability of the testing, more than three decades ago, an apparatus was described to study spatial learning and memory in laboratory rats (Morris et al. 1982). Since that time it has become one of the most influential and important methods in behavioural neurosciences (D’Hooge and De Deyn 2001; Fiore et al. 2000, 2002). Likewise, the virtual Morris water task is ordinarily used for investigating changes in spatial memory in humans. A study has shown sex differences in brain activation during a spatial navigation task in healthy adults due to a higher number of brain areas involved in spatial processing by women engaged in learning information about the environment (Sneider et al. 2011). An investigation on marijuana smokers revealed some impairments in the virtual Morris water task associated with parahippocampal hypoactivation, leading to differences in neuronal resources utilized during memory retrieval (Sneider et al. 2013b). However, the virtual Morris water task is mainly used to investigate spatial memory disruptions due to central nervous system human diseases involving, for the most part, the hippocampus and adjacent limbic areas. Recently, spatial navigation assessment has been used in patients affected by Alzheimer's disease 
(Possin et al. 2016; Wood 2016), by Huntington's disease (Begeti et al. 2016), in amnestic mild cognitive impairments (Migo et al. 2016), in patients affected by major depression (Cornwell et al. 2010), following the first episode of schizophrenia (Fajnerova et al. 2014), and in patients following traumatic brain injury (Skelton et al. 2000) such as hippocampal damage (Astur et al. 2002; Goodrich-Hunsaker et al. 2010) and vestibular dysfunction (Brandt et al. 2005; Hüfner et al. 2007).

\subsection{Statistical analyses}

ANOVA with alcohol dependence (AUD participants, control participants) and gender (females, males) as independent variables was used to analyze: $i$, the latency to the first movement in all trials; $i$, the latency to reach the hidden platform in the learning phase; $i i i$, the latency to reach the visible platform; $i v$ the total distance moved in all trials; $v$, the time spent in $\%$ in the quadrants with the hidden platform (probe trial). The latency to the first movement in all trials and the total distance moved in all trials were also analyzed with a 7-level repeated measure outcome. The data of the latency to reach the hidden platform in the learning phase were analyzed also with a 4-level repeated measure outcome while the data of the latency to reach the visible platform were analyzed also with a 2-level repeated measure outcome. Data analyses are based on the statistic used for the rodent Morris water maze (Aloe et al. 1999; Fiore et al. 2002). Post hoc comparisons within logical sets of means were performed by the Tukey's HSD test, the use of which is permissible or even recommended in the absence of significant main or interaction effects in the ANOVA in order to minimize frequency errors of both type I and type II (Wilcox 1987, pp.189-189). Effect size was measured by the Eta-squared $\left(\eta^{2}\right)$ test. Data were additionally analyzed with the smoking factor, cumulative abstinence day (CAD) and years of critical consumption as a covariate in the ANOVA analyses. 


\section{Results}

\subsection{Latency to the first movement in all trials (Trials 1-7)}

Figure 2 shows the latency to the first movement in all trials of the virtual Morris water task in AUD men and AUD women. ANOVA evidenced a gender effect with a general increase in latency in women $\left[F_{(1,60)}=6.91, p=0.01,\left(\eta^{2}=0.079\right)\right]$ particularly evident for control women in trials 1, 2, 3 and 6 (see post-hocs). Data showed also an interaction repeated measures, alcohol dependence and gender $\left[F_{(6,480)}=2.14\right.$, $\left.p=0.047,\left(\eta^{2}=0.026\right)\right]$. Indeed, increased latencies were more marked in alcoholics men compared to control men in trials 1, 2 and 6 as shown by post-hoc comparisons (ps $<0.05$ in trial 1,2 and 6 ).

\section{Figure 2 here}

\subsection{Latency to reach the hidden platform in the learning phase (Trials 1-4)}

Figure 3 shows the latency to reach the hidden platform in the 4 trials of the learning phase of the virtual Morris water task in AUD men and AUD women. A gender effect was revealed by data analysis with increased latency in seconds to reach the hidden platform in women $\left[F_{(1,80)}=6.99, p=0.099,\left(\eta^{2}=0.08\right)\right]$ changes more evident in trial 3 as shown by post-hoc comparisons $(\mathrm{ps}<0.05)$. An effect of alcohol dependence for higher values in alcoholics missed the statistical significance $\left[F_{(1,80)}=2.89, p=0.09\right.$, $\left.\left(\eta^{2}=0.035\right)\right]$. However, an interaction alcohol dependence and repeated measures was revealed by ANOVA $\left[F_{(3,240)}=2.55, p=0.05,\left(\eta^{2}=0.03\right)\right]$ due to a habituation profile in alcoholics (both men and women) compared to both controls. No differences were found for the other variables.

\section{Figure 3 here}




\subsection{Time spent in $\%$ in the quadrants of the probe trial (trial 5)}

Figure 4 shows the time spent (expressed as \%) in the quadrants of the probe trial (trial number 5) without the appearance of the platform of the virtual Morris water task in alcoholic men and women. ANOVA revealed the expected increased time spent in the target quadrant (North East - NE) of the participants compared to the other quadrants $\left[F_{(3,240)}=23.07, p<0.01\right.$, for the effect of the repeated measures, $\left(\eta^{2}=\right.$ 0.22)]. In particular, in the target quadrant, AUD persons (both men and women) spent less time when compared to control participants (both men and women) $\left[F_{(1,80)}=3.75, p=0.05\right.$, for the effect of alcohol dependence $\left(\eta^{2}=0.045\right)$; no gender effects were revealed]. Post-hocs analyses revealed also that in the target quadrant AUD men had worst performances when compared with control men $(p<0.05)$.

\section{Figure 4 here}

\subsection{Latency to reach the visible platform (trials 6 and 7)}

Figure 5 shows the latency in seconds to reach the visible platform of the virtual Morris water task in AUD men and AUD women. Data evidenced that alcoholic women showed highest latency time for reaching the visible platform as displayed by the significant gender effect in the ANOVA $\left[F_{(1,80)}=6.81, p=0.01,\left(\eta^{2}=0.078\right)\right]$ determining also a significant effect of the alcohol dependence $\left[F_{(1,80)}=6.61, p=0.012\right.$, $\left.\left(\eta^{2}=0.076\right)\right]$. In particular, post-hocs revealed that during trial 6 the latency times of alcoholic women were higher to those of both AUD men and control women $(\mathrm{ps}<0.05)$.

Figure 5 here 


\subsection{Total distance moved in all trials (trials 1-7)}

Figure 6 shows the total distance moved in all trials of the virtual Morris water task in AUD men and AUD women and their respective controls. Data showed the expected effect of the repeated measures during the testing for the low total distance moved by participants during trials 6 and $7\left[F_{(6,480)}=34.00, p<0.01,\left(\eta^{2}=0.29\right)\right]$. Furthermore, a different gender response in virtual locomotion was highlighted by ANOVA $\left[F_{(6,480)}=3.59, p<0.01\right.$ for the interaction repeated measures and gender, $\left.\left(\eta^{2}=0.04\right)\right]$. In particular, during trial 5 both alcoholic and control men had higher values compared to control and AUD women (ps $<0.05$ in post-hocs). Higher virtual locomotion during trial 6 was also observed for AUD women when compared to the values of AUD men and with control women ( $\mathrm{ps}<0.05$ in post-hocs). No differences were found for the other analyzed variables.

No effects of smoking, CAD or years of critical consumption as covariates were found in all the analyzed factors.

Figure 6 here 


\section{Discussion}

This is the first investigation on gender differences in spatial navigation to show that the behavioural responses in a virtual Morris water task may be impaired in AUD men and AUD women.

We have used a spatial memory paradigm related to navigation and not to spatial memory in the micro space making this study more comparable with preclinical studies that is the main novelty point of the work (Fiore et al. 2002). This aspect could be relevant more generally in studying the effect of addiction to specific substances (e.g, not only ethanol but also cannabis) that have an impact on the brain structure that is crucial for spatial memory and navigation: the hippocampus (Chersi and Burgess 2015). Indeed, so far, studies that have investigated spatial cognition on human participants with a history of addiction to substance that seems to affect the hippocampus are few (and often have used paper and pencil tests in the micro space) and (1) have mixed samples of men and women, but (1a) did not take into account the effect of gender (Beatty et al. 1996; Sneider et al. 2013b) or (1b) after detecting an overall gender effect decided to not investigate it further in the experimental sample (see Beatty et al. 1996), or (2) investigated only men (Ceccanti et al. 2015b) although sometimes this has been specifically planned (e.g., (Palermo et al. 2012).

Based on the present results such changes resulted to be quite different between AUD men and AUD women. In particular, elevated latency to the first movement in all trials was observed only in AUD men (trials 1, 2, and 6). However, a gender difference was also revealed since control women had higher latencies compared to control men in trials 1, 2, 3 and 6 . Increased time spent to reach the hidden platform in the learning phase was found for women of both groups compared to men, in particular during trial 3. As predicted AUD persons (more evident in men) spent less time in the target 
quadrant during the probe trial, however, quite interestingly AUD women had higher latencies to reach the platform in the visible condition during trials 6 and 7 that resulted to be associated higher distance moved. As for the probe trial men of both groups showed increased virtual locomotion compared to the women of both groups. However, it could be considered further differential strategies on the maze task in women compared to men explaining the sex differences to initiate movement and to locate the platform.

As for the topic gender plus addiction plus spatial navigation the present study shows that AUD men and AUD women may have different responses in the virtual Morris task especially in the total distance moved in all trials and in the latency to reach the visible platform. The present investigation confirms and extends previous studies showing $i$ : different gender responses in spatial learning tasks; $i i$ : some alterations due to alcohol addiction in virtual spatial learning and iii: differences between AUD men and AUD women in spatial behavioural related paradigms.

As for the human gender differences (Astur et al. 2016) it has shown that males are faster and make more correct responses in mental rotation tasks (Voyer et al. 1995). It has been well established that males outperform females on measures assessing overall virtual water maze performance (Astur et al. 1998) where adult males were faster in locating the hidden platform during training, a finding replicated in children (Newhouse et al. 2007). These investigations also found that when the platform was removed in the probe trial following training, males revealed a stronger search preference for the former platform quadrant. Also, gender differences have been shown in several navigation paradigms including real-life route-learning tasks (Saucier et al. 2002) and virtual reality simulations (Astur et al. 1998).

A possible mechanism mediating apparent sex differences on overall task execution in humans is the extent to which distal characteristics of the environment can be effectively used. Two points of distal information believed to be essential to navigation 
in the water maze are (1) distal stimuli, defined as distinct visual features of the environment located outside the pool wall and (2) the size and shape of the room in which the pool is located (Sandstrom et al. 1998). The pool wall itself and reference points situated within its boundaries can also be utilized, and are referred to as proximal stimuli. It has been shown (Sandstrom et al. 1998) that men performed better than women when the geometry of the room was the only helpful source of distal information available. Quite interestingly, other studies (Saucier et al. 2002) demonstrated in a realworld navigation task that women displayed a preference in using landmark data, while men preferred cardinal directions (e.g. North, East) and distances. To investigate which visual features in the environment were utilized during virtual water maze responses, it was studied eye movements during the first $3 \mathrm{~s}$ of each trial. Whereas both men and women focussed towards distal features of the environment importantly longer than the pool wall or search area, shorter trial latencies in men corresponded with a somewhat longer focus on distal cues, and quicker visual investigation of the environment early during training (Mueller et al. 2008). These data suggest that overall sex differences might originate from the ability of men to faster learn and discriminate crucial features of the distal environment. Other significant effects of age and sex were observed for path length navigation in the target region (narrower spatial sampling), and heading error, with young adults performing better than adolescents, and an overall male advantage in the virtual Morris water task (Sneider et al. 2015). Young adults performed better than older adults, with a male advantage being evident in both age groups (Schoenfeld et al. 2010). In a virtual Morris water task, 8-10-year-old children again revealed a male advantage in spatial ability, with boys performing better on the probe trial than girls (Newhouse et al. 2007).

In regard to alcohol addiction and spatial memory, these findings do confirm and extend our previous data showing that alcohol addiction may elicit motor control, attentional and motivational changes in the virtual Morris task (Ceccanti et al. 2015b) 
involving also secondary effects of deficits in other cognitive domains. In other words, the findings of differences in latency on learning trials without differences in distance plus the impairment on the visible platform condition may challenge any interpretation of spatial memory deficit. The visible platform condition of the Morris water maze is intended as a control condition for non-specific/non-spatial factors including motivation and motor control factors, among others. These factors are also inherent to the spatial learning trials. Thus, when navigation to a visible proximal cue is impaired, clear interpretation of spatial memory abilities is not possible.

Ethanol addiction is known to elicit marked changes in memory and learning performances and motivated behaviours including spatial memory and place preference as shown by both animal models and humans studies (Fiore et al. 2009; Fontaine et al. 2016; Novier et al. 2015b). Children with Fetal Alcohol Syndrome are impaired at place learning but not in cued-navigation (Hamilton et al. 2003) as measured by decreased time spent searching in the correct quadrant during the probe trial, despite similar motor control, attention and motivation. In an early report with different methods of investigation detoxified AUD people had impairments in visuospatial scanning, construction, utilizing and manipulating information from visual images but the remote spatial memory was not significantly affected (Beatty et al. 1996).

In conclusion, based on the multidirectional toxic effects of ethanol in both brain and other organs the findings of the present study in AUD men and AUD women may indicate a sex-dependent spectrum of changes in the virtual Morris task associated with alcohol abuse effects. However, additional studies are required to elucidate these changes since some potentially confounding factors might have influenced the present results such as the limited number of participants who underwent the virtual Morris maze (mainly for women of both groups, although without significant effect size results), the former use by patients and also by healthy men and women of 
psychoactive drugs, as well as the fact that some of the enrolled patients and controls were heavy smokers. Other possible limits of a human study based on preliminary interviews is the reliability of the interviews per se, although such interviews were carried out by highly trained personnel. 


\section{References}

Astur, R.S., Ortiz, M.L., and Sutherland, R.J. 1998. A characterization of performance by men and women in a virtual Morris water task: a large and reliable sex difference. Behav. Brain Res. 93:185-90.

Astur, R.S., Purton, A.J., Zaniewski, M.J., Cimadevilla, J., and Markus E.J., 2016. Human sex differences in solving a virtual navigation problem. Behav. Brain Res. 308:236-243.

Astur, R.S., Taylor, L.B., Mamelak, A.N., Philpott, L., and Sutherland, R.J. 2002. Humans with hippocampus damage display severe spatial memory impairments in a virtual Morris water task. Behav. Brain Res. 132:77-84.

Beatty, W.W., Hames, K.A., Blanco, C.R., Nixon, S.J., and Tivis, L.J. 1996. Visuospatial perception, construction and memory in alcoholism. J. Stud. Alcohol, 57:136-43.

Begeti, F., Schwab, L.C., Mason, S.L., and Barker, R.A. 2016. Hippocampal dysfunction defines disease onset in Huntington's disease. J. Neurol. Neurosurg. Psychiatry, 87(9):975-81. doi:10.1136/jnnp2015-312413

Bosco, A., Longoni, A.M., and Vecchi, T. 2004. Gender effects in spatial orientation: cognitive profiles and mental strategies. Appl. Cogn. Psychol. 18:519-532. doi:10.1002/acp.1000

Brandt, T., Schautzer, F., Hamilton, D.A., Bruning, R., Markowitsch, H.J., Kalla, R., et al. 2005. Vestibular loss causes hippocampal atrophy and impaired spatial memory in humans. Brain, 128:2732-41. doi:10.1093/brain/awh61

Brown, S.A., Tapert, S.F., Granholm, E., and Delis, D.C. 2000. Neurocognitive functioning of adolescents: effects of protracted alcohol use. Alcohol Clin. Exp. Res. 24:164-71.

Ceccanti, M., Carito, V., Vitali, M., Iannuzzi, S., Tarani, L., De Nicolò, S., et al. 2015a. Serum BDNF and NGF Modulation by Olive Polyphenols in Alcoholics during Withdrawal. J. Alcohol. Drug Depend. 3:1-6. doi: 10.4172/23296488.1000214

Ceccanti, M., Hamilton, D., Coriale, G., Carito, V., Aloe, L., Chaldakov, G., et al. 2015b. Spatial learning in men undergoing alcohol detoxification. Physiol. Behav. 149:324-330. doi:10.1016/j.physbeh.2015.06.034

Chersi, F., and Burgess, N. 2015. The Cognitive Architecture of Spatial Navigation: Hippocampal and Striatal Contributions. Neuron, 88:64-77. doi:10.1016/j.neuron.2015.09.021

Cornwell, B.R., Salvadore, G., Colon-Rosario, V., Latov, D.R., Holroyd, T., Carver, F.W., et al. 2010. Abnormal hippocampal functioning and impaired spatial navigation in depressed individuals: evidence from whole-head magnetoencephalography. Am. J. Psychiatry, 167:836-44. doi:10.1176/appi.ajp.2009.09050614

D'Hooge, R., and De Deyn, P.P. 2001. Applications of the Morris water maze in the study of learning and memory. Brain Res. Brain Res. Rev. 36:60-90.

Erol, A., and Karpyak, V.M. 2015. Sex and gender-related differences in alcohol use and its consequences: Contemporary knowledge and future research considerations. Drug Alcohol Depend. 156:1-13. doi:10.1016/j.drugalcdep.2015.08.023

Fajnerova, I., Rodriguez, M., Levcik, D., Konradova, L., Mikolas, P., Brom, C., et al. 2014. A virtual reality task based on animal research - spatial learning and memory in patients after the first episode of schizophrenia. Front. Behav. Neurosci. 8:157. doi:10.3389/fnbeh.2014.00157

Fein, G., Torres, J., Price, L.J., and Di Sclafani, V. 2006. Cognitive performance in long-term abstinent alcoholic individuals. Alcohol Clin. Exp. Res. 30:1538-44. doi:10.1111/j.1530- 
0277.2006.00185.x

Fiore, M., Angelucci, F., Alleva, E., Branchi, I., Probert, L., and Aloe, L. 2000. Learning performances, brain NGF distribution and NPY levels in transgenic mice expressing TNF-alpha. Behav. Brain Res. 112:165-75.

Fiore, M., Korf, J., Antonelli, A., Talamini, L., and Aloe, L. 2002. Long-lasting effects of prenatal MAM treatment on water maze performance in rats: associations with altered brain development and neurotrophin levels. Neurotoxicol. Teratol. 24:179-91.

Fiore, M., Laviola, G., Aloe, L., di Fausto, V., Mancinelli, R., and Ceccanti, M., 2009. Early exposure to ethanol but not red wine at the same alcohol concentration induces behavioral and brain neurotrophin alterations in young and adult mice. Neurotoxicology. 30:59-71.

Fontaine, C.J., Patten, A.R., Sickmann, H.M., Helfer, J.L., and Christie, B.R. 2016. Effects of pre-natal alcohol exposure on hippocampal synaptic plasticity: Sex, age and methodological considerations. Neurosci. Biobehav. Rev. 64:12-34. doi:10.1016/j.neubiorev.2016.02.014

Goodrich-Hunsaker, N.J., Livingstone, S.A., Skelton, R.W., and Hopkins, R.O. 2010. Spatial deficits in a virtual water maze in amnesic participants with hippocampal damage. Hippocampus, 20:481-91. doi:10.1002/hipo.20651

Hamilton, D.A., Driscoll, I., and Sutherland, R.J. 2002. Human place learning in a virtual Morris water task: some important constraints on the flexibility of place navigation. Behav. Brain Res. 129:159-70.

Hamilton, D.A., Johnson, T.E., Redhead, E.S., and Verney, S.P. 2009. Control of rodent and human spatial navigation by room and apparatus cues. Behav. Process. 81:154-69. doi:10.1016/j.beproc.2008.12.003

Hamilton, D.A., Kodituwakku, P., Sutherland, R.J., and Savage, D.D. 2003. Children with Fetal Alcohol Syndrome are impaired at place learning but not cued-navigation in a virtual Morris water task. Behav. Brain Res. 143:85-94.

Harvanko, A.M., Odlaug, B.L., Schreiber, L.R., and Grant, J.E. 2012. Cognitive task performance and frequency of alcohol usage in young adults. J. Addict. Med. 6:106-11. doi:10.1097/ADM.0b013e31823ae56d

Holmila, M., and Raitasalo, K. 2005. Gender differences in drinking: why do they still exist? Addict. Abingdon Engl. 100:1763-1769. doi:10.1111/j.1360-0443.2005.01249.x

Hüfner, K., Hamilton, D.A., Kalla, R., Stephan, T., Glasauer, S., Ma, J., et al. 2007. Spatial memory and hippocampal volume in humans with unilateral vestibular deafferentation. Hippocampus, 17:471-485. doi:10.1002/hipo.20283

Kramer, J.H., Kaplan, E., Blusewicz, M.J., and Preston, K.A. 1991. Visual hierarchical analysis of Block Design configural errors. J. Clin. Exp. Neuropsychol. 13:455-65. doi:10.1080/01688639108401063

Migo, E.M., O’Daly, O., Mitterschiffthaler, M., Antonova, E., Dawson, G.R., Dourish, C.T., et al. 2016. Investigating virtual reality navigation in amnestic mild cognitive impairment using fMRI. Neuropsychol. Dev. Cogn. B Aging Neuropsychol. Cogn. 23:196-217. doi:10.1080/13825585.2015.1073218

Morris, R.G., Garrud, P., Rawlins, J.N., and O'Keefe, J. 1982. Place navigation impaired in rats with hippocampal lesions. Nature, 297:681-3. 
Mueller, S.C., Jackson, C.P., and Skelton, R.W. 2008. Sex differences in a virtual water maze: an eye tracking and pupillometry study. Behav. Brain Res. 193:209-15. doi:10.1016/j.bbr.2008.05.017

Newhouse, P., Newhouse, C., and Astur, R.S. 2007. Sex differences in visual-spatial learning using a virtual water maze in pre-pubertal children. Behav. Brain Res. 183:1-7. doi:10.1016/j.bbr.2007.05.011

Nixon, S.J., Prather, R., and Lewis, B. 2014. Sex differences in alcohol-related neurobehavioral consequences. Handb. Clin. Neurol. 125:253-272. doi:10.1016/B978-0-444-62619-6.00016-1

Novier, A., Diaz-Granados, J.L., and Matthews, D.B. 2015. Alcohol use across the lifespan: An analysis of adolescent and aged rodents and humans. Pharmacol. Biochem. Behav. 133:65-82. doi:10.1016/j.pbb.2015.03.015

Oscar-Berman, M., and Marinkovic, K. 2007. Alcohol: effects on neurobehavioral functions and the brain. Neuropsychol. Rev. 17:239-57. doi:10.1007/s11065-007-9038-6

Oscar-Berman, M., and Marinkovic, K. 2003. Alcoholism and the brain: an overview. Alcohol Res. Health, 27:125-33.

Palermo, L., Bianchini, F., Iaria, G., Tanzilli, A., and Guariglia, C. 2012. Assessing topographical orientation skills in cannabis users. ScientificWorldJournal, 2012:137071. doi: $10.1100 / 2012 / 137071$

Palermo, L., Iaria, G., and Guariglia, C. 2008. Mental imagery skills and topographical orientation in humans: a correlation study. Behav. Brain Res. 192:248-253. doi:10.1016/j.bbr.2008.04.014

Piccardi, L., Iaria, G., Ricci, M., Bianchini, F., Zompanti, L., and Guariglia, C. 2008. Walking in the Corsi test: which type of memory do you need? Neurosci. Lett. 432:127-131. doi:10.1016/j.neulet.2007.12.044

Pitel, A.-L., Eustache, F., and Beaunieux, H., 2014. Component processes of memory in alcoholism: pattern of compromise and neural substrates. Handb. Clin. Neurol. 125:211-225. doi:10.1016/B978-0-444-62619-6.00013-6

Possin, K.L., Sanchez, P.E., Anderson-Bergman, C., Fernandez, R., Kerchner, G.A., Johnson, E.T., et al. 2016. Cross-species translation of the Morris maze for Alzheimer's disease. J. Clin. Invest. 126:779-783. doi:10.1172/JCI78464

Sandstrom, N.J., Kaufman, J., and Huettel, S.A. 1998. Males and females use different distal cues in a virtual environment navigation task. Brain Res. Cogn. Brain Res. 6:351-360.

Saucier, D.M., Green, S.M., Leason, J., MacFadden, A., Bell, S., and Elias, L.J. 2002. Are sex differences in navigation caused by sexually dimorphic strategies or by differences in the ability to use the strategies? Behav. Neurosci. 116:403-410.

Scaife, J.C., and Duka, T. 2009. Behavioural measures of frontal lobe function in a population of young social drinkers with binge drinking pattern. Pharmacol. Biochem. Behav. 93:354-62. doi:10.1016/j.pbb.2009.05.015

Schoenfeld, R., Lehmann, W., and Leplow, B. 2010. Effects of age and sex in mental rotation and spatial learning from virtual environments. J. Individ. Differ. 31:78-82. DOI: 10.1027/1614$0001 / \mathrm{a} 000014$.

Schottenbauer, M.A., Hommer, D., and Weingartner, H. 2007. Memory deficits among alcoholics: performance on a selective reminding task. Neuropsychol. Dev. Cogn. B Aging Neuropsychol. Cogn. 14:505-16. doi:10.1080/13825580600681305 
Skelton, R.W., Bukach, C.M., Laurance, H.E., Thomas, K.G., and Jacobs, J.W. 2000. Humans with traumatic brain injuries show place-learning deficits in computer-generated virtual space. J. Clin. Exp. Neuropsychol. 22:157-75. doi:10.1076/1380-3395(200004)22:2;1-1;ft157

Skinner, H.A., and Sheu, W.J. 1982. Reliability of alcohol use indices. The Lifetime Drinking History and the MAST. J. Stud. Alcohol, 43:1157-70.

Sneider, J.T., Cohen-Gilbert, J.E., Crowley, D.J., Paul, M.D., and Silveri, M.M. 2013a. Differential effects of binge drinking on learning and memory in emerging adults. J. Addict. Res. Ther. Suppl. 7. doi:10.4172/2155-6105.s7-006

Sneider, J.T., Gruber, S.A., Rogowska, J., Silveri, M.M., and Yurgelun-Todd, D.A. 2013b. A preliminary study of functional brain activation among marijuana users during performance of a virtual water maze task. J. Addict. 2013:461029. doi:10.1155/2013/461029

Sneider, J.T., Hamilton, D.A., Cohen-Gilbert, J.E., Crowley, D.J., Rosso, I.M., and Silveri, M.M. 2015. Sex differences in spatial navigation and perception in human adolescents and emerging adults. Behav. Processes, 111:42-50. doi:10.1016/j.beproc.2014.11.015

Sneider, J.T., Sava, S., Rogowska, J., and Yurgelun-Todd, D.A. 2011. A preliminary study of sex differences in brain activation during a spatial navigation task in healthy adults. Percept. Mot. Ski. 113:461-80.

Sobell, L.C. 1992. Timeline follow-back: A technique for assessing self-reported alcohol consumption., Measuring Alcohol Consumption: Psychosocial and Biochemical Methods. Humama Press, Totowa, NJ. USA.

Voyer, D., Voyer, S., and Bryden, M.P. 1995. Magnitude of sex differences in spatial abilities: a metaanalysis and consideration of critical variables. Psychol. Bull. 117:250-270.

Weissenborn, R., and Duka, T. 2003. Acute alcohol effects on cognitive function in social drinkers: their relationship to drinking habits. Psychopharmacol. Berl. 165:306-12. doi:10.1007/s00213-0021281-1

Wilcox, R.R. 1987. New Statistical Procedures for the Social Sciences. Hillsdale, N.J.: L. Erlbaum Associates.

Wood, H. 2016. Alzheimer disease: A virtual Morris maze to assess cognitive impairment in Alzheimer disease. Nat. Rev. Neurol. 12:126. doi:10.1038/nrneurol.2016.16 
Figure 1. Schematic reproduction of a virtual Morris maze. The circular pool (A) is in the center of a room whereas the platform is located in the north-east quadrant of the pool (target). Panel B represents a monitor-based first-person perspective from the center of the circular pool.

(A)
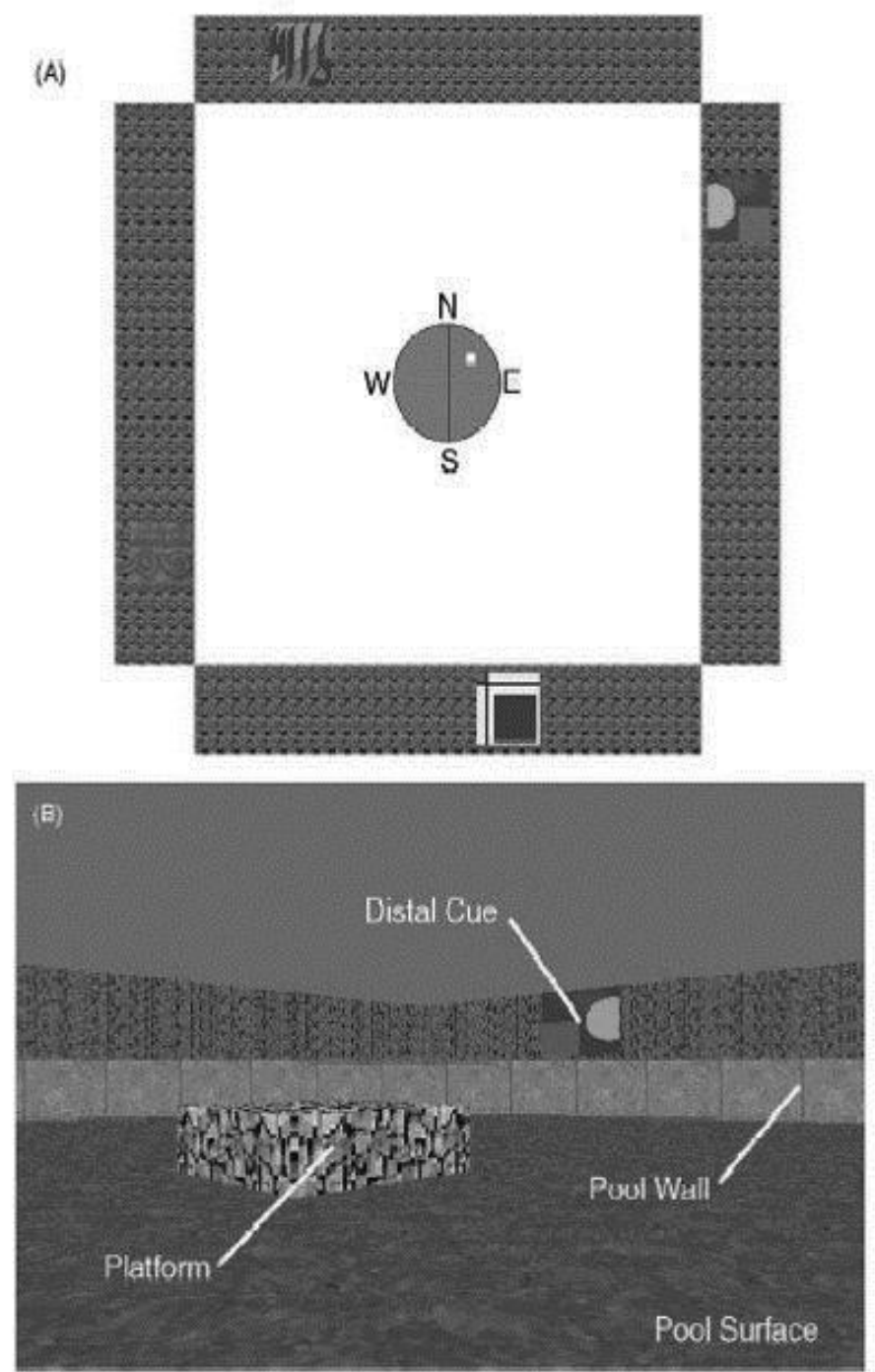
Figure 2. The figure shows the latency to the first movement in all trials in AUD men and AUD women undergoing alcohol detoxification and respective controls. The vertical lines in the figure indicate pooled standard error means (SEM) derived from appropriate error mean square in the ANOVA. Asterisks indicate significant differences between groups $(* p<0.05)$.

Latency to the First Movement in all Trials

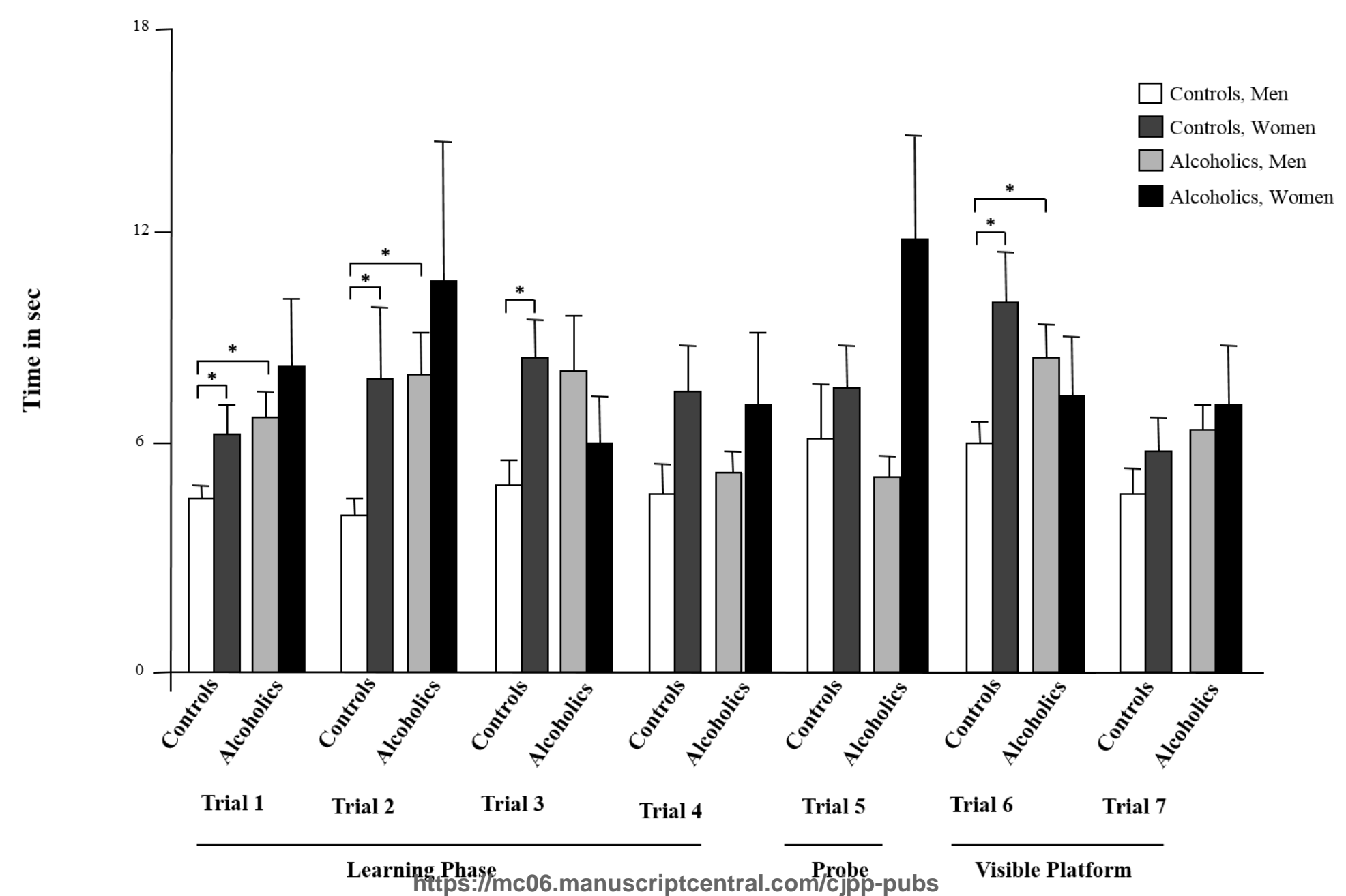


Figure 3. The figure shows the latency to reach the hidden platform in the learning phase (trials 1-4) in AUD men and AUD women undergoing alcohol detoxification and respective controls. The vertical lines in the figure indicate pooled standard error means (SEM) derived from appropriate error mean square in the ANOVA. Asterisks indicate significant differences between groups $(* p<0.05)$.

Latency to Reach the Hidden Platform in the Learning Phase

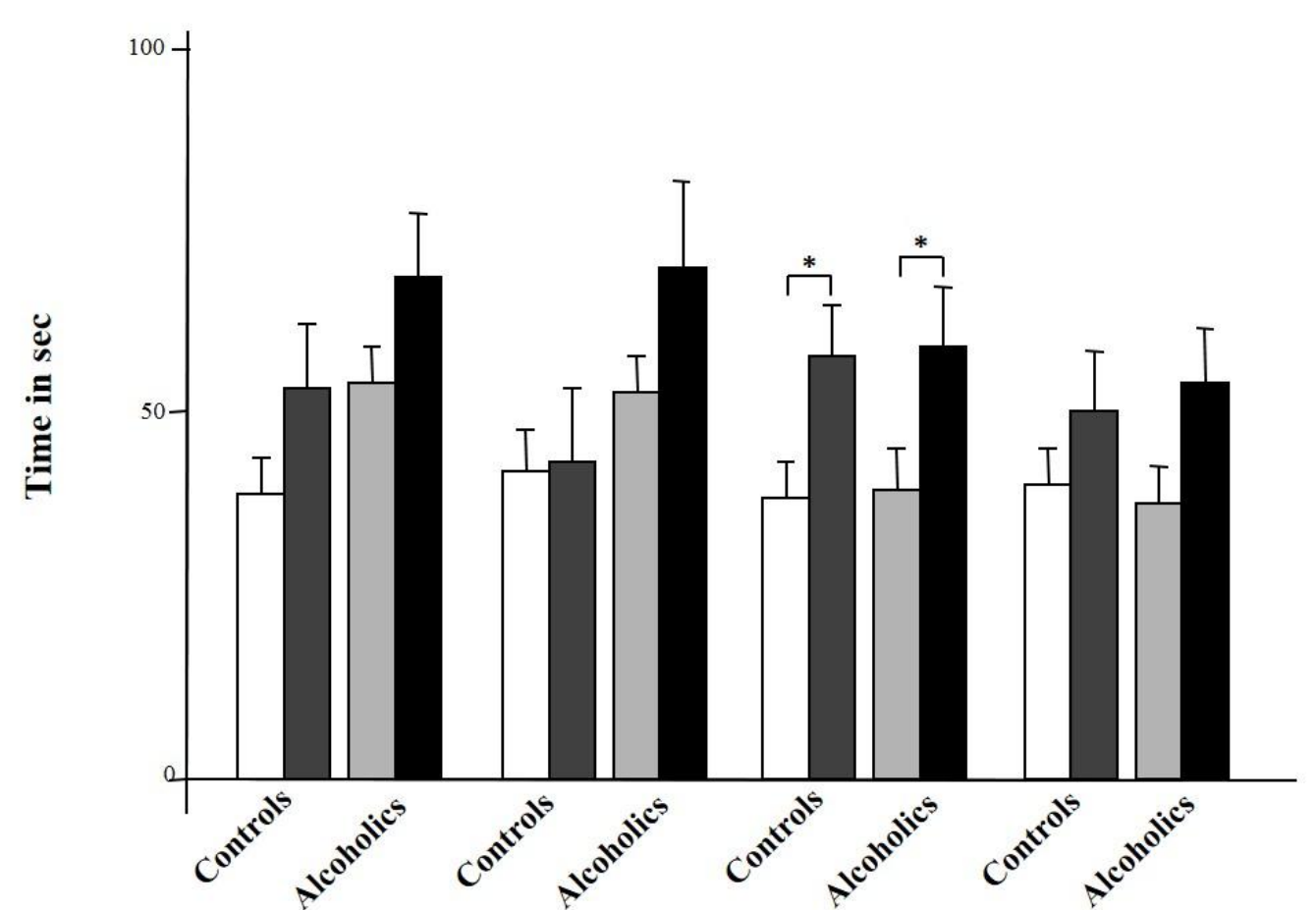

$\square$ Controls, Men

$\square$ Controls, Women

$\square$ Alcoholics, Men

Alcoholics, Women

Trial 1 httpfríme06.manusqriptrgntral.comtcipip-pubs 
Figure 4. The figure shows the time spent in percentage in the target quadrant (North-East, South-East, NorthWest, South-West) with the hidden platform (probe trial - trial number 5). The vertical lines in the figure indicate pooled standard error means (SEM) derived from appropriate error mean square in the ANOVA. Asterisks indicate significant differences between groups $\left({ }^{*} p<0.05\right)$.

\section{Time Spent in \% in the Quadrants of the Probe Trial}

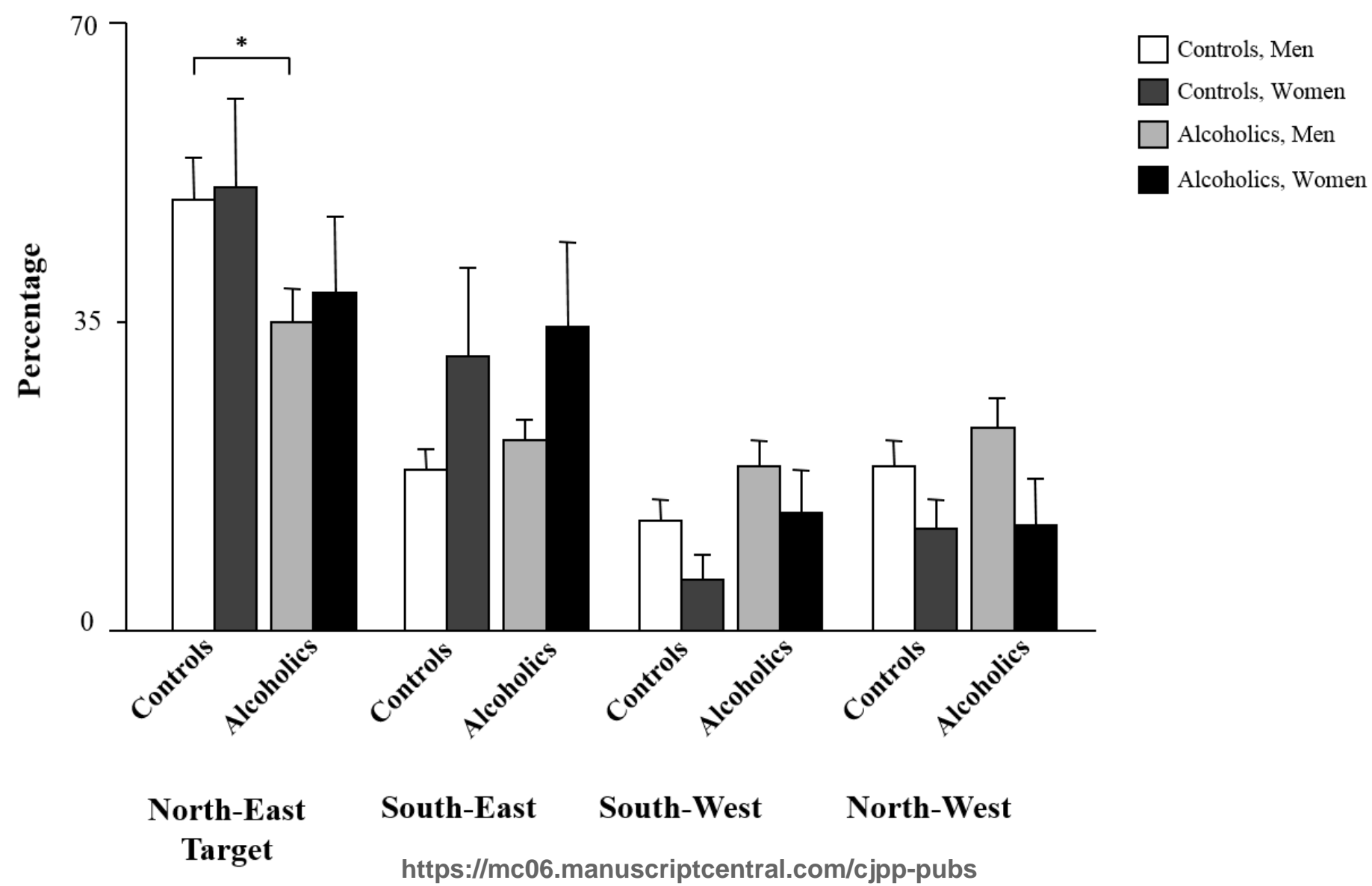


Figure 5. The figure shows the latency to reach the visible platform (trials 6 and 7) in AUD men and AUD women undergoing detoxification and respective controls. The vertical lines in the figure indicate pooled standard error means (SEM) derived from appropriate error mean square in the ANOVA. Asterisks indicate significant differences between groups $(* p<0.05)$.

\section{Latency to Reach the Visible Platform}

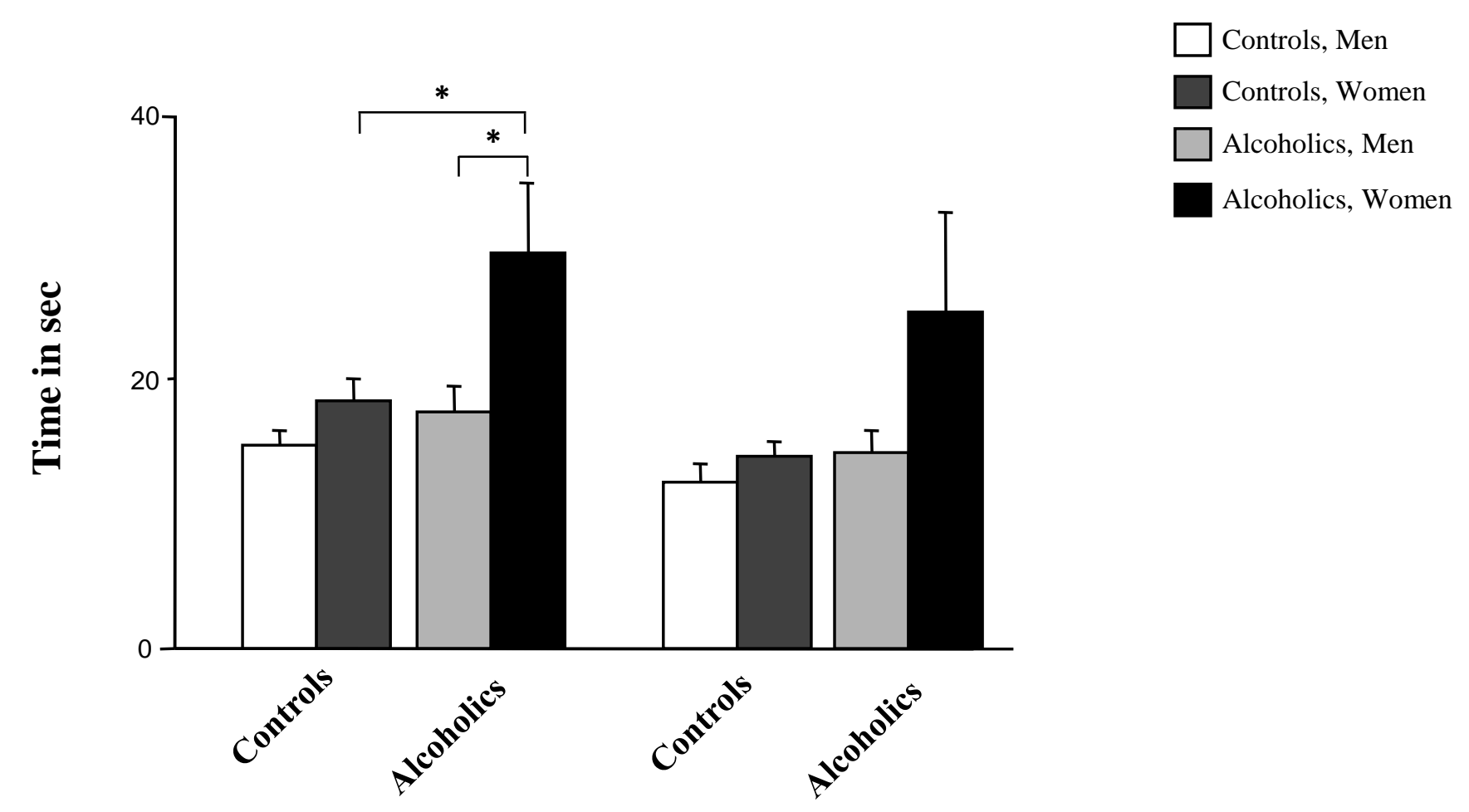

Trial 6

Trial 7

https://mc06.manuscriptcentral.com/cjpp-pubs 
Figure 6. The figure shows the total distance moved in all trials in AUD men and AUD women undergoing detoxification and respective controls. The vertical lines in the figure indicate pooled standard error means (SEM) derived from appropriate error mean square in the ANOVA. Asterisks indicate significant differences between groups $\left({ }^{*} p<0.05 ; * * p<0.01\right)$.

\section{Total Distance Moved in all Trials}

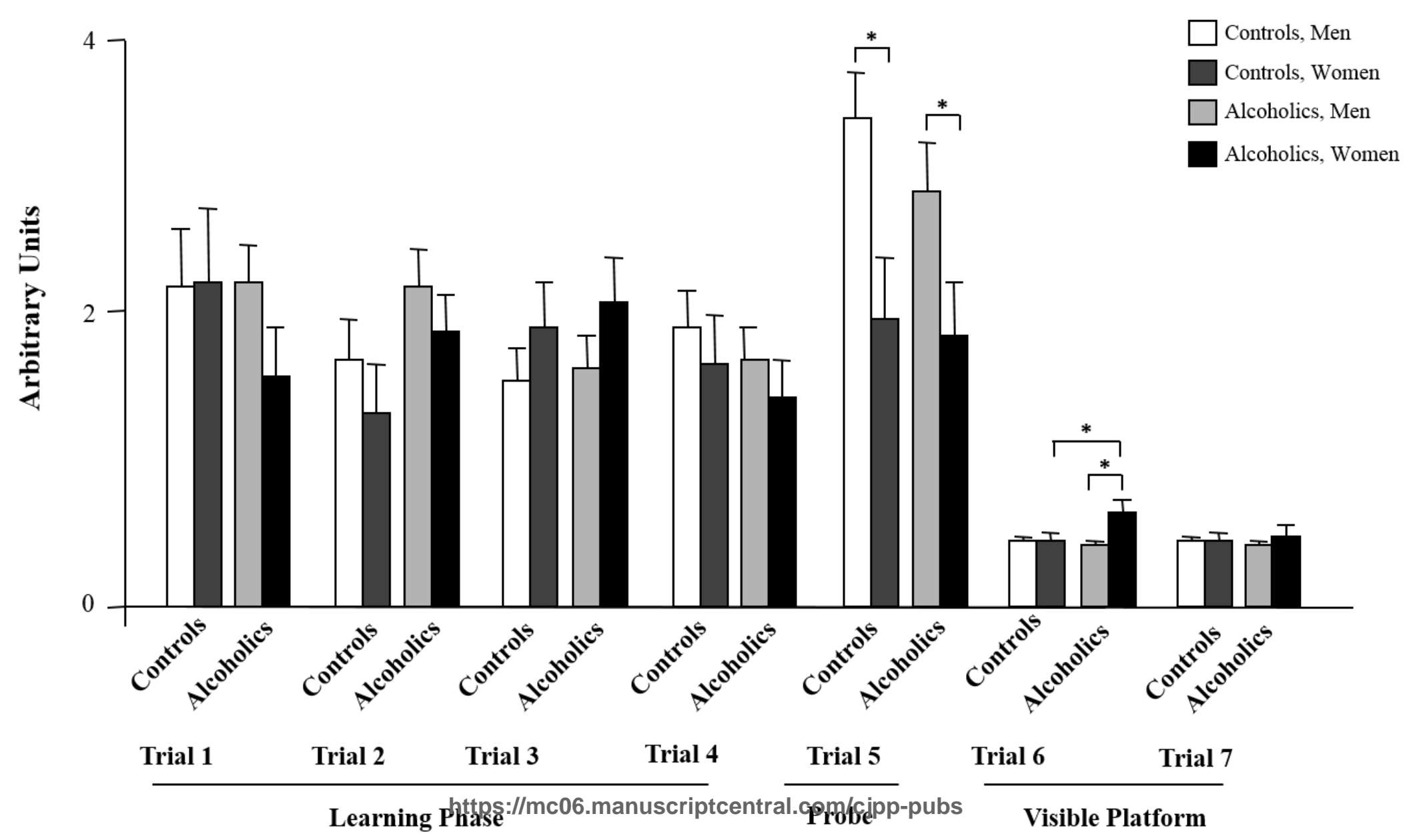

